\title{
Capnocytophaga canimorsus blebitis: case report and review of literature
}

\author{
Michael C. Yang, John Ling and Sameh Mosaed ${ }^{*}$ (D)
}

\begin{abstract}
Background: Capnocytophaga canimorsus is a facultative anaerobic, slow-growing, capnophilic, Gram-negative bacillus, that is commonly found in the microflora of canine and feline oral cavities. Capnocytophaga infections are an emerging zoonotic disease that can cause fatal systemic infections in immunocompromised individuals. Localized ocular Capnocytophaga infections, including keratitis, blepharitis, and endophthalmitis, can lead to severe eye threatening situations. To our knowledge, there is currently no documented case of Capnocytophaga canimorsus blebitis with bleb perforation after trabeculectomy.

Case presentation: Our case report and literature review features a novel case of Capnocytophaga blebitis that occurred after trabeculectomy, associated with close dog contact (i.e. face licking). The patient had underwent trabeculectomy 10 years prior and presented with conjunctival injection, perforated bleb, and hypotony. Overall, patient was medically treated subconjunctival vancomycin, gentamicin and moxifloxacin drops. Trabeculectomy revision was performed with good visual outcome. Bacterial cultures grew Capnocytophaga canimorsus.

Conclusions: We discuss the strategies for diagnosis, treatment, and common risk factors for ocular Capnocytophaga infections. At-risk patients with ocular infections should be asked about close contact with dogs and cats; and treated promptly with the proper antibiotic regimen.
\end{abstract}

Keywords: Capnocytophaga canimorsus, Blebitis, Trabeculectomy, Bleb perforation, Bleb-associated infections, Case report

\section{Background}

Pet ownership has many benefits, with some studies reporting a lower risk of cardiovascular disease and mortality with dog ownership [1]. This cohabitation also comes with its own risks; half of all Americans will be bitten at least once in their lifetime [2]. Capnocytophaga canimorsus is commonly found in canine oral microflora, and less commonly in cats. In certain studies, $C$. canimorsus could be cultured from oral secretions of approximately $26 \%$ of dogs and $18 \%$ of cats [3]. Recent reports have shown the prevalence to be up to $74 \%$ of dogs [4]. C. canimorsus can cause a wide variety of infections, with a majority being systemic infections and less

* Correspondence: smosaed@hs.uci.edu

Department of Ophthalmology, Gavin Herbert Eye Institute, University of California, Irvine, CA 92697, USA than $10 \%$ being localized infections [5]. Many of these localized infections have been ocular; reports include blepharitis, keratitis, and endophthalmitis [6-8]. However, to our knowledge, there has not yet been a reported case of blebitis linked to $C$. canimorsus. We present a case of $C$. canimorsus blebitis with bleb perforation, which highlights the virulence of $C$. canimorsus and the need for pet owners with predisposing risk factors to be vigilant of ocular exposures.

\section{Case presentation}

An 81-year-old man was referred by an outside ophthalmologist with bacterial blebitis and perforated bleb, 10 years after trabeculectomy. Patient's medical history was unremarkable. His ocular history includes radial keratotomy, penetrating keratoplasty (PKP), and the

(c) The Author(s). 2021 Open Access This article is licensed under a Creative Commons Attribution 4.0 International License, which permits use, sharing, adaptation, distribution and reproduction in any medium or format, as long as you give appropriate credit to the original author(s) and the source, provide a link to the Creative Commons licence, and indicate if changes were made. The images or other third party material in this article are included in the article's Creative Commons licence, unless indicated otherwise in a credit line to the material. If material is not included in the article's Creative Commons licence and your intended use is not permitted by statutory regulation or exceeds the permitted use, you will need to obtain permission directly from the copyright holder. To view a copy of this licence, visit http://creativecommons.org/licenses/by/4.0/ The Creative Commons Public Domain Dedication waiver (http://creativecommons.org/publicdomain/zero/1.0/) applies to the data made available in this article, unless otherwise stated in a credit line to the data. 
aforementioned trabeculectomy 10 years prior. Upon presentation, patient's exam was notable for significant conjunctival injection, elevated cystic bleb, positive Seidel's test with significant flow, and intraocular pressure of $4 \mathrm{mmHg}$ (Fig. 1). Best corrected vision was 20/100. Corneal exam revealed fine keratic precipitates (KP) and evidence of PKP with mild haze around the periphery of the graft. Anterior chamber exam revealed trace cell and flare. Fundus exam was unremarkable except for cup-todisc ratio of 0.85 . No cells seen in vitreous. Given exam findings and concern for infection, patient was given subconjunctival injection of vancomycin $25 \mathrm{mg}$ and gentamicin $20 \mathrm{mg}$. Conjunctival samples and scrapings were sent for fungal and bacterial cultures. Patient was prescribed a prolonged course of moxifloxacin drops; initially every $1 \mathrm{~h}$ and eventually tapered to four times a day. Prednisolone acetate drops were added, and the patient was monitored regularly in clinic with improvement to his clinical condition.

Two weeks after initial presentation, trabeculectomy revision was performed involving closure of the bleb, excision of necrotic tissue and scleral patch graft (Fig. 2). Several months after surgery, patient continued to be Seidel's negative with normal intraocular pressure, and best corrected vision was 20/70 (Fig. 3). Per standard protocol at our institution, samples were plated on sheep blood, chocolate, Mac Conkey agar, Brucella agar, phenyl ethyl alcohol agar, split plate (Bacteroides Bile Esculin, Laked Brucella agar with Kanamycin and Vancomycin), and thioglycolate. Given initial appearance as a rare bacillus species, cultures were sent to County of Orange, Health Care Agency, Public Health

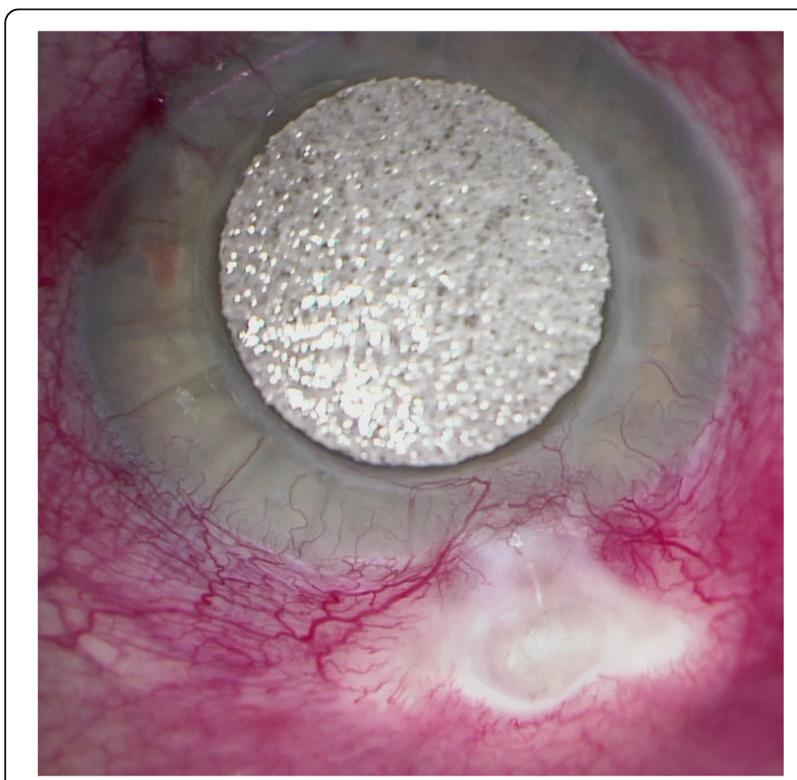

Fig. 1 Capnocytophaga blebitis, preoperative clinical image. Significant injection, cystic bleb, with associated bleb leakage
Laboratory for final identification of C. canimorsus species. Further details regarding identification and isolation were unavailable from the Public Health Laboratory however, C. canimorsus has been known to grow on 5\% sheep blood or chocolate agar in 5-10\% $\mathrm{CO}_{2}$ at $37 \mathrm{C}$ [5].

The diagnosis of $C$. canimorsus was initially suggested by appearance on Gram stain at our institution and final identification was made at aforementioned laboratory (Fig. 4). Further confirmation of C. canimorsus was obtained through DNA sequencing from an outside laboratory. The diagnosis of Capnocytophaga canimorsus was also confirmed independently by the referring ophthalmologist's cultures and testing. Fungal cultures were negative. Upon further questioning, patient revealed that he had a Dalmatian dog with poor dentition that frequently licked his face.

\section{Discussion and conclusion}

Capnocytophaga canimorsus is a Gram-negative bacillus that is capnophilic, a facultative anaerobe, and belongs in the Bacteroidetes phylum. It was originally named CDC group dysgonic fermenter 2 (DF-2), with articles published in the 1980s referring to Capnocytophaga canimorsus as DF-2. The first human infection was reported in 1976, and there has only been approximately 500 reported cases worldwide [9]. This is likely an underreported figure given that $C$. canimorsus is notoriously difficult to culture, and can also result in subclinical infections [10]. C. canimorsus can be transmitted through bites, scratches, and close animal contact (e.g. licking) [5].

With recent advances in ribosomal DNA sequencing, some researchers have proposed splitting Capnocytophaga canimorsus into two different species. The proposed name of the subclinical strain is Capnocytophaga canis, and maintaining the same name of Capnocytophaga canimorsus for the clinically symptomatic strain. However, recent case reports have isolated C. canis from patients with sepsis [11]. The strains that are harmful to humans all grow in heat-inactivated human serum, deglycosylate IgM and are cytochrome-oxidase positive [4]. Healthy, immunocompetent individuals are typically not susceptible to overt systemic C. canimorsus infections. However, at-risk individuals (e.g. immunocompromised, alcoholics, splenectomized patients) can have systemic C. canimorsus infections like endocarditis, meningitis, and even fatal bacteremia leading to multi-organ system failure [12-15].

Localized C. canimorsus infections have been mostly identified in the eye; keratitis being the most common presentation. Capnocytophaga keratitis is an aggressive cornea infection; in a study of ten patients, $50 \%$ required enucleation and 30\% required corneal transplant [16]. Given its capnophilic nature, Capnocytophaga has a 

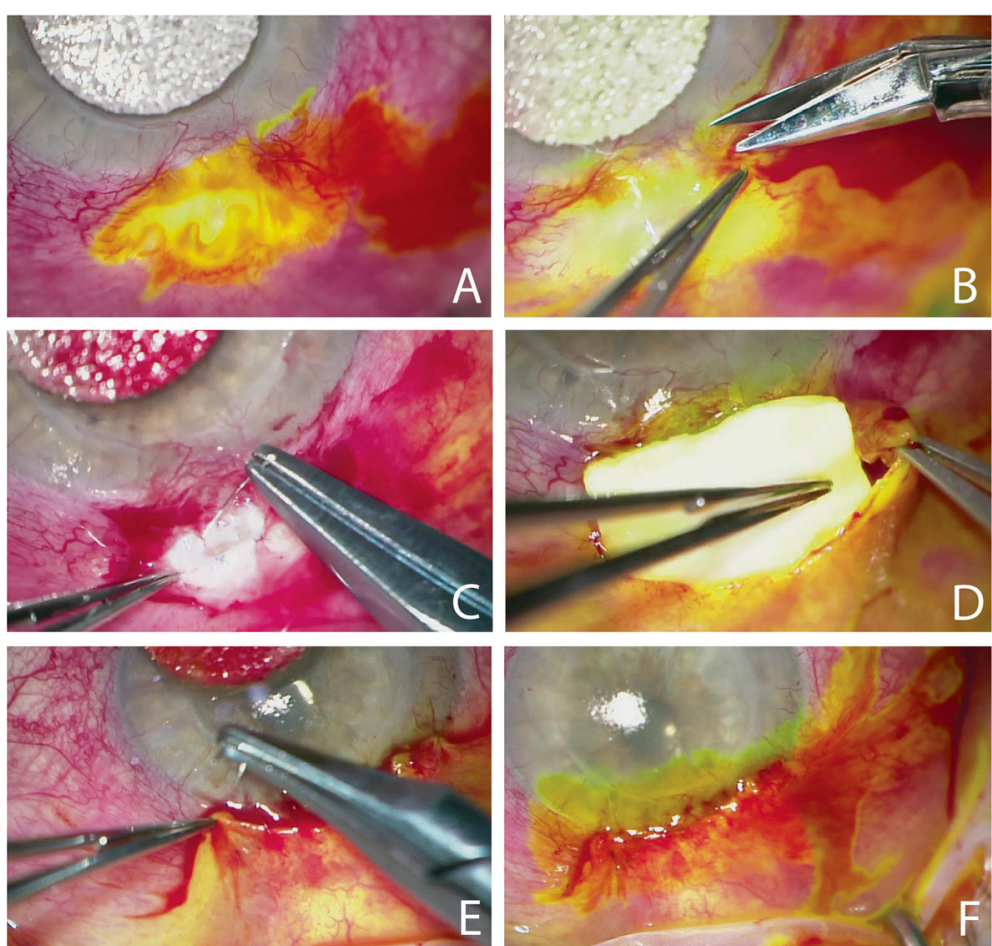

Fig. 2 Capnocytophaga blebitis, intraoperative images of trabeculectomy revision. a Seidel positive, indicating bleb leakage. b Limbus dissection. c Flap closure with 10-0 Prolene suture, interrupted. d Placement of scleral patch graft secured with 8-0 Vicryl sutures. e Conjunctival closure with 10-0 Vicryl sutures, running. $\mathbf{f}$ Watertight closure confirmed with Seidel negative

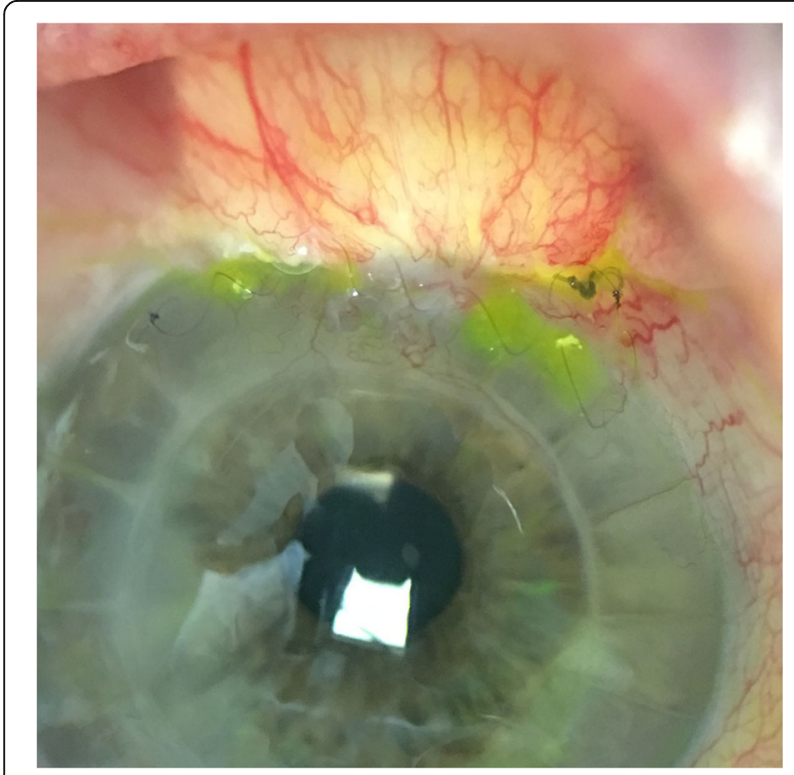

Fig. 3 Capnocytophaga blebitis, 4 weeks postoperative clinical image. Status post bleb closure, excision of necrotic tissue and scleral patch graft. No bleb leakage, dissolving running suture visualized at limbus predilection for the deeper layers of the corneal stroma. Patients often present with corneal edema, endothelial lesions, ring-shaped infiltrates, and corneal perforation. Like our presented case, patients with Capnocytophaga keratitis report frequent and close interactions with dogs (e.g. face licking) [17]. Patients susceptible to Capnocytophaga keratitis are often immunocompromised-for

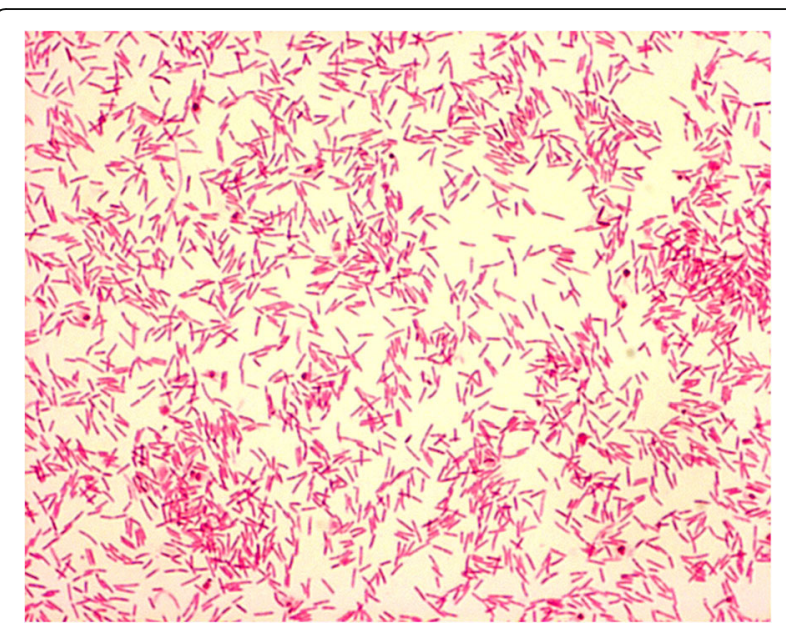

Fig. 4 Capnocytophaga canimorsus Gram stain image. Gram negative rods, fusiform cells generally $1-3 \mu \mathrm{m}$ in length. Sample culture image obtained with permission from Microbe-Canvas team 
example, status post bone marrow transplant, or rituximab infusions. Professions that are regularly exposed to canine and feline mouths (i.e. veterinarians) are also at risk [7]. Topical clindamycin has been used with good clinical results in some patients $[7,16,17]$. Some clinicians have also used oral clindamycin to achieve higher levels of antibiotics in the anterior chamber and deeper layers of the cornea where Capnocytophaga resides.

The reported incidence of bleb-associated infections (BAI) range from 1.5 to $4.8 \%$ at 5 years follow up. BAIs range from stage I with no cell in the anterior chamber and little to no visual impairment to stage IIIB with cell in the anterior chamber and vitreous with an obscured view of the fundus [18]. Early BAI occurs within the first post-operative month, and late BAI occurs after the first month. Our case of Capnocytophaga blebitis is a late BAI and stage II (cell in anterior chamber, no cell in vitreous). Diagnostic workup can include aqueous/vitreous stain and culture, polymerase chain reaction (PCR), biome representational in silico karyotyping (BRiSK), or metagenomic deep sequencing (MDS) [16-18]. The most commonly isolated microorganisms in early onset BAI is coagulase negative Staphylococcus, and late onset BAI is Streptococcus. There is currently no consensus on the most effective treatment for BAI. However, commonly used treatment regimens are fortified aminoglycosides (e.g. tobramycin $(14 \mathrm{mg} / \mathrm{mL}$ ) with vancomycin (q30 $\mathrm{min}$ ) or 4th generation fluoroquinolone (q1 hour) [19]. These antibiotics broadly cover Gram-negative and Gram-positive microorganisms. Of note, Capnocytopha$g a$ 's susceptibility to aminoglycosides and vancomycin varies widely between studies; but is typically susceptible to clindamycin, penicillin, cephalosporin, imipenem, and beta-lactamase inhibitor combinations $[7,20]$. Our patient was initially treated with subconjunctival vancomycin and gentamicin; and eventually shifted to a prolonged course of topical moxifloxacin with treatment success. Subconjunctival antibiotics are not routinely administered; however, our patient was elderly and the typical regimen of q30 min eyedrops of vancomycin and aminoglycoside was not possible. Additionally, given the urgency of acute blebitis and the importance of prompt administration of antibiotics, we opted for a broad spectrum approach with vancomycin and gentamicin before culture sensitivities were available. Given its high lipophilicity, topical moxifloxacin achieves high intraocular concentrations in aqueous humor and conjunctiva. Moxifloxacin covers broadly for Gram-negative, Gram-positive and atypical pathogens [18].

Capnocytophaga canimorsus is a member of the complex microflora of canine and feline oral cavities. In immunocompromised patients, C. canimorsus has been known to cause severe systemic infections like bacteremia and multi-organ failure. In rare cases, $C$. canimorsus can cause eye-threatening ocular infections ranging from keratitis to endophthalmitis. Our novel case of Capnocytophaga blebitis contributes to the scarce clinical information available regarding ocular Capnocytophaga infections. At-risk patients with ocular infections should be asked about close contact with dogs and cats; and treated promptly with the proper antibiotic regimen.

\section{Abbreviations \\ PKP: Penetrating keratoplasty; KPP: Keratic precipitates; CDCP: Centers for Disease Control; DF-2P: Dysgonic fermenter 2; BAIP: Bleb-associated infections; PCRP: Polymerase chain reaction; BRiSKP: Biome representational in silico karyotyping; MDSP: Metagenomic deep sequencing}

\section{Acknowledgements}

Thank you to Dr. Mosaed and Dr. Ling for all their support. Special thanks to the team at Microbe-Canvas for the generous contribution of the Gram stain image of C. canimorsus.

\section{Authors' contributions}

MY drafted manuscript and performed literature review of related topics including: C. canimorsus and blebitis treatment strategies. JL \& SM significant contributions in conception and acquisition of data, revision of manuscript, as well as direct patient care involved in case. All authors read and approved the final manuscript.

Funding

No financial support.

\section{Availability of data and materials}

Data sharing is not applicable to this article as no datasets were generated or analyzed during the current study.

Ethics approval and consent to participate

Need for approval from ethics was waived.

\section{Consent for publication}

Written consent for the publication of identifying clinical/personal information and images was obtained from the patient.

\section{Competing interests}

The authors declare that they have no competing interests.

Received: 23 December 2019 Accepted: 20 January 2021

Published online: 26 January 2021

\section{References}

1. Mubanga M, Byberg L, Nowak C, Egenvall A, Magnusson PK, Ingelsson E, Fall T. Dog ownership and the risk of cardiovascular disease and death - a nationwide cohort study. Sci Rep. 2017;7(1):15821. https://doi.org/10.1038/ s41598-017-16118-6 PubMed PMID: 29150678; PubMed Central PMCID: PMC5693989.

2. Griego RD, Rosen T, Orengo IF, Wolf JE. Dog, cat, and human bites: a review. J Am Acad Dermatol. 1995;33(6):1019-29. https://doi.org/10.1016/ 0190-9622(95)90296-1 Review. PubMed PMID: 7490347.

3. Blanche P, Bloch E, Sicard D. Capnocytophaga canimorsus in the oral flora of dogs and cats. J Inf Secur. 1998;36(1):134 PubMed PMID: 9515691.

4. Renzi F, Dol M, Raymackers A, Manfredi P, Cornelis GR. Only a subset of C. canimorsus strains is dangerous for humans. Emerg Microbes Infect. 2015; 4(8):e48. https://doi.org/10.1038/emi.2015.48 Epub 2015 Aug 19. PubMed PMID: 26421271; PubMed Central PMCID: PMC4576167.

5. Lion C, Escande F, Burdin JC. Capnocytophaga canimorsus infections in human: review of the literature and cases report. Eur J Epidemiol. 1996; 12(5):521-33 Review. PubMed PMID: 8905316.

6. Glasser DB. Angular blepharitis caused by gram-negative bacillus DF-2. Am J Ophthalmol. 1986;102(1):119-20. https://doi.org/10.1016/00029394(86)90222-9 PubMed PMID: 3728612. 
7. Chodosh J. Cat's tooth keratitis: human corneal infection with Capnocytophaga canimorsus. Cornea. 2001;20(6):661-3 PubMed PMID: 11473172.

8. Thommen F, Opota O, Greub G, Jaton K, Guex-Crosier Y, Wolfensberger TJ, Matet A. Capnocytophaga canimorsus endophthalmitis after cataract surgery linked to salivary dog-to-human transmission. Retin Cases Brief Rep. 2017. https://doi.org/10.1097//CB.0000000000000637 [Epub ahead of print] PubMed PMID: 28957954

9. Butler T. Capnocytophaga canimorsus: an emerging cause of sepsis, meningitis, and post-splenectomy infection after dog bites. Eur J Clin Microbiol Infect Dis. 2015;34(7):1271-80.

10. Janda JM, Graves MH, Lindquist D, Probert WS. Diagnosing Capnocytophaga canimorsus infections. Emerg Infect Dis. 2006;12(2):340-2. https://doi.org/10.3201/eid1202.050783 PubMed PMID: 16494769; PubMed Central PMCID: PMC3373098.

11. Suzuki M, Imaoka K, Haga Y, et al. Characterization of three strains of Capnocytophaga canis isolated from patients with sepsis. Microbiol Immunol. 2018;62(9):567-73.

12. Sandoe JA. Capnocytophaga canimorsus endocarditis. J Med Microbiol. 2004;53(Pt 3):245-8. https://doi.org/10.1099/jmm.0.05274-0 Review. PubMed PMID: 14970251

13. van Samkar A, Brouwer MC, Schultsz C, van der Ende A, van de Beek D. Capnocytophaga canimorsus meningitis: three cases and a review of the literature. Zoonoses Public Health. 2016;63(6):442-8. https://doi.org/10.1111/ zph.12248 Epub 2015 Dec 23. Review. PubMed PMID: 26693951.

14. Taquin $\mathrm{H}$, Roussel $\mathrm{C}$, Roudière L, Besancon A, Hubiche T, Kaidomar M, Edouard S, Del Giudice P. Fatal infection caused by Capnocytophaga canimorsus. Lancet Infect Dis. 2017;17(2):236. https://doi.org/10.1016/S14733099(16)30200-6 PubMed PMID: 28134123.

15. Langguth $P$, Leissner L, Zick G, Fischer A, Stuhlmann-Laiesz C, Salehi Ravesh M, Austein F, Jansen O, Both M. Why Asplenic patients should not take Care of the Neighbour's dog? A Fatal Course of Capnocytophaga canimorsus Sepsis. Case Rep Infect Dis. 2018;2018:3870640. https://doi.org/10.1155/ 2018/3870640 eCollection 2018. PubMed PMID: 30174969; PubMed Central PMCID: PMC6098898.

16. Alexandrakis G, Palma LA, Miller D, Alfonso EC. Capnocytophaga keratitis. Ophthalmology. 2000;107(8):1503-6. https://doi.org/10.1016/s01616420(00)00227-x PubMed PMID: 10919898

17. Seitzman GD, Thulasi P, Hinterwirth A, Chen C, Shantha J, Doan T. Capnocytophaga keratitis: clinical presentation and use of metagenomic deep sequencing for diagnosis. Cornea. 2019;38(2):246-8. https://doi.org/10. 1097/ICO.0000000000001790 PubMed PMID: 30346341; PubMed Central PMCID: PMC6322945.

18. Razeghinejad MR, Havens SJ, Katz LJ. Trabeculectomy bleb-associated infections. Surv Ophthalmol. 2017;62(5):591-610. https://doi.org/10.1016/j. survophthal.2017.01.009 Epub 2017 Feb 8. Review. PubMed PMID: 28188728.

19. Reynolds AC, Skuta GL, Monlux R, Johnson J. Management of blebitis by members of the American Glaucoma Society: a survey. J Glaucoma. 2001; 10(4):340-7 PubMed PMID: 11558820.

20. Jolivet-Gougeon A, Sixou J-L, Tamanai-Shacoori Z, Bonnaure-Mallet M. Antimicrobial treatment of Capnocytophaga infections. Int J Antimicrob Agents. 2007;29(4):367-73.

\section{Publisher's Note}

Springer Nature remains neutral with regard to jurisdictional claims in published maps and institutional affiliations.

Ready to submit your research? Choose BMC and benefit from:

- fast, convenient online submission

- thorough peer review by experienced researchers in your field

- rapid publication on acceptance

- support for research data, including large and complex data types

- gold Open Access which fosters wider collaboration and increased citations

- maximum visibility for your research: over $100 \mathrm{M}$ website views per year

At BMC, research is always in progress.

Learn more biomedcentral.com/submissions 